\title{
Capillary blood flow to ovarian follicles, stroma and corpora lutea of anaesthetized sheep
}

\author{
N. W. Bruce* and R. M. Moor \\ Nuffield Institute for Medical Research, University of Oxford, \\ Headley Way, Headington, Oxford, OX $39 \mathrm{DS}$, \\ and A.R.C. Unit of Reproductive Physiology and Biochemistry, \\ 307 Huntingdon Road, Cambridge CB3 0JQ, U.K.
}

\begin{abstract}
Summary. The radioactive microsphere technique was used to determine the rate of blood flow through vessels of up to $15 \mu \mathrm{m}$ diameter in the ovaries of 23 anaesthetized sheep in the $72 \mathrm{hr}$ preceding ovulation. The validity of the microsphere technique was established in two preliminary studies.

On Days 14, 15 and 16 of the cycle the rate of blood flow (ml. $\mathrm{min}^{-1} .100 \mathrm{~g}^{-1}$ tissue) was 1122,708 and 116 to the CL; 157, 258 and 140 to the stroma; and 637, 742 and 1096 to the follicles, respectively. Blood flow to grossly atretic follicles did not differ significantly from that to non-atretic follicles of an equivalent size. Change in blood flow do not appear to initiate or control the activation, steroidogenic function or atresia of follicles.
\end{abstract}

\section{Introduction}

The distribution of blood flow within the ovary has not been clearly defined, although alterations in vascularity appear to be inherent in the early response of these organs to hormonal stimulation (Wurtman, 1964; Szego, 1965). The radioactive microsphere technique provides a convenient means of determining accurately blood flow rates to the internal organs of the body (Rudolf \& Heymann, 1972). We have used this procedure to study the pattern of blood flow to the follicles, stroma and $\mathrm{CL}$ of sheep during the $72 \mathrm{hr}$ preceding ovulation.

\section{Materials and Methods}

Animals

Mature Welsh Mountain ewes that had undergone at least two normal oestrous cycles before treatment were used. The mean length of the oestrous cycle for the ewes in the flock from which the experimental animals were obtained was $16 \cdot 5 \pm 0 \cdot 3$ days. Blood flow measurements were made on 25 ewes; two were used for preliminary technical validation trials, seven were examined on Day 14, six on Day 15 and ten on Day 16 of the oestrous cycle.

\section{Experimental procedure}

Anaesthesia was induced with a nitrous oxide-halothane (Fluothane: I.C.I., Macclesfield, Cheshire) mixture. The ewes were intubated and thereafter maintained under light anaesthesia with a mixture of $1.8 \%$ halothane in oxygen. With the ewe in the supine position the left or right brachial artery and both femoral arteries were catheterized. A catheter was passed down the left carotid artery until its tip lay within the left ventricle as shown by pulse pressure changes. The brachial and

\footnotetext{
* Present address: Department of Anatomy and Human Biology, University of Western Australia, Nedlands, Western Australia, 6009.
} 
diagonally opposite femoral arterial catheters were connected to two syringes, mounted on a Harvard Infusion Pump, which had been set to withdraw blood at a constant rate of $20 \mathrm{ml}$. $\mathrm{min}^{-1}$. The remaining femoral arterial catheter was connected to a pressure transducer and pulse rate meter. A uniform interval of $60 \mathrm{~min}$ was allowed to elapse between the induction of anaesthesia and the injection of microspheres. The injection, consisting of $1,082,000 \pm 49,000{ }^{46} \mathrm{Sc}$-labelled microspheres with a diameter of $15 \pm 5 \mu \mathrm{m}$ (3M Co., St Paul, Minnesota, U.S.A.) suspended in $20 \mathrm{ml}$ physiological saline, was administered into the left ventricle over a $20-\mathrm{sec}$ period. The cardiac catheter was flushed with a further $50 \mathrm{ml}$ saline over the following $10 \mathrm{sec}$. The withdrawal of blood from the brachial and femoral arteries was begun $5 \mathrm{sec}$ before the injection of microspheres and continued for $25 \mathrm{sec}$ after the completion of the above injection procedure.

The ewes were killed by an intra-cardiac injection of sodium pentobarbitone after the microsphere injection. The ovaries were removed, weighed and dissected into luteal, stromal and follicular compartments. Atretic follicles were identified under a stereoscopic microscope as having an opaque appearance, poor external vascularization and an irregular and often detached membrana granulosa; large lipoidal droplets were sometimes seen in the follicular fluid. It has been established that the macroscopic and subsequent histological assessment of atresia agree in over $97 \%$ of instances (M. F. Hay \& R. M. Moor, unpublished observations). The remaining follicles in the present study were non-atretic or were in the very early stages of atresia; no attempt was made to differentiate between these two classes of follicles.

A calibrated eyepiece was used to measure the diameter of each follicle. Thereafter, the follicle was punctured, drained free of follicular fluid, blotted dry and weighed in an hermetically sealed container. The relationship between the diameter and mass of the atretic and non-atretic follicle populations was determined but as the difference between the two populations was not significant the following single equation was established:

$$
Y=0 \cdot 524\left(D^{3}-(D-0 \cdot 236)^{3}\right)
$$

where $\mathrm{D}=$ diameter of the follicle in $\mathrm{mm}$ and $\mathrm{Y}=$ wet weight of the tissue in $\mathrm{mg}$.

The radioactivity of the individual follicles, stroma, CL and blood samples was measured with a Philips A.G.A. well-type counter.

Blood samples were taken after the microsphere injection and assayed for plasma progesterone by a competitive protein-binding assay (Seamark, Moor \& Mclntosh, 1974).

\section{Validation of the microsphere technique}

The technical problems associated with the injection of microspheres, the measurement of radioactivity in samples of tissue and blood and the final calculation of blood flow have already been described (Abdul-Karim \& Bruce, 1973). However, the use of microspheres to measure follicular blood flow in sheep presented some difficulties not normally encountered.

Microspheres theoretically mix evenly with the blood in the left ventricle and distribute throughout the body in the same proportion as the distribution of cardiac output. Blood samples withdrawn from the brachial and femoral arteries at the same rate of flow, $20 \mathrm{ml} \cdot \mathrm{min}^{-1}$, should therefore receive the same number of microspheres. However, Buckberg et al. (1971) found that in the sheep there were $6 \%$ more microspheres in the femoral than in the carotid blood samples. Since our results were similar to those of the above workers, we adopted their suggestion and used the femoral reference sample to estimate cardiac output and ovarian blood flow.

Although there were discrepancies in the longitudinal distribution of microspheres the bilateral distribution was more consistent. Blood flow to the left and right kidney was 207 and $205 \mathrm{ml}$. $\mathrm{min}^{-1}$. $100 \mathrm{~g}^{-1}$, respectively $(r=0.98, n=48)$. Blood flow to relatively small organs, the left and right oviducts, was 22 and $23 \mathrm{ml} \cdot \mathrm{min}^{-1} .100 \mathrm{~g}^{-1}$, respectively $(r=0 \cdot 89, n=48)$. The mean percentage of the cardiac output apparently distributed to the lung was high, $8.4 \% \pm 0 \cdot 8$ (S.E.M.), which suggested that a proportion of microspheres passed through arterio-venous shunts of greater than $15 \mu \mathrm{m}$ diameter to return to the right side of the heart and thence to the lungs. All the blood flow results in the present work thus refer only to flow through vessels of less than $15 \mu \mathrm{m}$ diameter. Larger spheres could have been used but the smaller spheres are distributed more like red blood cells, occlude less 
of the vascular bed, are less variable in size and more of them can be injected without causing cardiovascular changes which may themselves affect the experiment (Buckberg et al., 1971).

The major problem of the present experiment was to ensure that individual follicles received sufficient spheres to provide a meaningful estimate of blood flow. In an early trial we found that the average follicle received about $0.001 \%$ of the cardiac output. Thus, of the $1,000,000^{46} \mathrm{Sc}$ microspheres injected into the left ventricle, around 10 microspheres would have lodged in the average follicle. The theoretical standard deviation of a follicular flow estimate due to technical limitations would have been around $30 \%$ of the mean for ${ }^{46} \mathrm{Sc}$ spheres (Buckberg et al., 1971). In practice, the standard deviations of follicular blood flow due to technical limitations and biological variation was in the order of $50 \%$. The standard error of the mean was considerably lower due to the large number of follicles studied.

\section{Results}

Of the various parameters used to indicate the general physiological status of the ewes on Days 14 $(\mathrm{N}=7), 15(\mathrm{~N}=6)$ and $16(\mathrm{~N}=10)$, mean $( \pm$ S.E.M.) blood pressure $(72 \pm 4 ; 80 \pm 6 ; 82 \pm 4 \mathrm{mmHg})$, pulse rate $(107 \pm 8 ; 103 \pm 9 ; 100 \pm 6 / \mathrm{min})$ and cardiac output $\left(60 \pm 6 ; 72 \pm 8 ; 64 \pm 4 \mathrm{ml} \cdot \mathrm{min}^{-1} \cdot \mathrm{kg}^{-1}\right)$ were relatively uniform, but there were marked differences in peripheral plasma progesterone levels $\left(3 \cdot 3 \pm 0.5 ; 3 \cdot 2 \pm 0 \cdot 7 ; 0.2 \pm 0.06 \mathrm{ng} \cdot \mathrm{ml}^{-1}\right)$.

Table 1. Mean ( \pm S.E.M.) tissue weight $(\mathrm{mg})$, rate of blood flow through capillaries $15 \mu \mathrm{m}$ in diameter $\left(\mathrm{ml} . \mathrm{min}^{-1}\right.$. $100 \mathrm{~g}^{-1}$ ) and the percentage distribution of blood perfusing the major components of the ovaries of sheep during the $72 \mathrm{hr}$ preceding ovulation

\begin{tabular}{|c|c|c|c|c|c|c|}
\hline & \multicolumn{3}{|c|}{ Ovary with corpus luteum } & \multicolumn{3}{|c|}{ Ovary without corpus luteum } \\
\hline & Day 14 & Day 15 & Day 16 & Day 14 & Day 15 & Day 16 \\
\hline No. of sheep & 7 & 6 & 10 & 7 & 6 & 10 \\
\hline \multicolumn{7}{|l|}{ Total ovary } \\
\hline Weight & $1380 \pm 160$ & $1200 \pm 120$ & $1100 \pm 120$ & $680 \pm 120$ & $560 \pm 40$ & $740 \pm 80$ \\
\hline Blood flow & $587 \pm 63$ & $478 \pm 141$ & $149 \pm 25^{* *}$ & $181 \pm 50$ & $286 \pm 98$ & $147 \pm 27$ \\
\hline \multicolumn{7}{|l|}{ Corpus luteum } \\
\hline Weight & $620 \pm 50$ & $500 \pm 40$ & $340 \pm 60^{* *}$ & & & \\
\hline Blood flow & $1122 \pm 169$ & $708 \pm 203$ & $116 \pm 19 * *$ & & & \\
\hline$\%$ of total ovarian flow & $8 \overline{4}$ & $6 \overline{5}$ & $2 \overline{8}$ & & & \\
\hline \multicolumn{7}{|l|}{ Stroma } \\
\hline Weight & $730 \pm 140$ & $670 \pm 100$ & $730 \pm 80$ & $650 \pm 120$ & $530 \pm 40$ & $720 \pm 80$ \\
\hline Blood flow & $157 \pm 33$ & $266 \pm 76$ & $160 \pm 37$ & $157 \pm 35$ & $249 \pm 79$ & $121 \pm 24$ \\
\hline$\%$ of total ovarian flow & $\overline{14}$ & 32 & 58 & 86 & $\overline{86}$ & $7 \overline{5}$ \\
\hline \multicolumn{7}{|l|}{ Follicles (non-atretic) } \\
\hline No. per ovary & $7 \cdot 1 \pm 1 \cdot 9$ & $5.8 \pm 1.6$ & $7 \cdot 3 \pm 1 \cdot 1$ & $8.7 \pm 1.8$ & $6 \cdot 8 \pm 2 \cdot 1$ & $7 \cdot 4 \pm 2 \cdot 4$ \\
\hline Weight & $2.8 \pm 0.4$ & $3.2 \pm 0.6$ & $3.5 \pm 0.9$ & $3 \cdot 2 \pm 0.7$ & $5 \cdot 1 \pm 1 \cdot 7$ & $3.4 \pm 0.5$ \\
\hline Blood flow & $668 \pm 135$ & $776 \pm 173$ & $1069 \pm 247$ & $604 \pm 116$ & $692 \pm 142$ & $1101 \pm 171 *$ \\
\hline \multicolumn{7}{|l|}{ Follicles (grossly atretic) } \\
\hline No. per ovary & $2 \cdot 3 \pm 0.7$ & $2.8 \pm 0.8$ & $3.1 \pm 0.6$ & $3.6 \pm 0.8$ & $2 \cdot 8 \pm 1 \cdot 3$ & $2.9 \pm 0.4$ \\
\hline Weight & $2 \cdot 9 \pm 1 \cdot 2$ & $4 \cdot 1 \pm 2 \cdot 2$ & $1.9 \pm 0.7$ & $1.9 \pm 0.6$ & $2 \cdot 9 \pm 1 \cdot 1$ & $2 \cdot 2 \pm 0.7$ \\
\hline Blood flow & $447 \pm 115$ & $878 \pm 228$ & $1083 \pm 329$ & $741 \pm 179$ & $762 \pm 208$ & $1062 \pm 317$ \\
\hline \multicolumn{7}{|l|}{ Follicles (combined) } \\
\hline$\%$ of total ovarian flow & 2 & 3 & 14 & 14 & 14 & 25 \\
\hline
\end{tabular}

Variation between Days significant; ${ }^{*} P<0 \cdot 05 ;{ }^{* *} P<0 \cdot 01$.

The mean weights and associated blood flow data for the whole ovaries and for their separate luteal, stromal and follicular components are given in Table 1. Total ovarian weight did not alter significantly during the follicular phase, despite the large decreases $(P<0.01)$ in the weight of the CL between Day 14 and Day 16. The mean weight of follicles appeared to increase slightly, but not 
significantly, between Day 14 and Day 15. The weights of normal and atretic follicles were similar and were unaffected by the presence or absence of a CL within the ovary.

Total blood flow to the ovary with the CL fell significantly $(P<0 \cdot 01)$ from $587 \mathrm{ml} . \mathrm{min}^{-1} .100 \mathrm{~g}^{-1}$ tissue on Day 14 to $149 \mathrm{ml} \cdot \mathrm{min}^{-1} .100 \mathrm{~g}^{-1}$ tissue on Day 16 , and paralleled a decline in luteal flow; blood flow to the other ovary remained relatively constant during this period. The decline in luteal blood flow was proportionally much greater than the decline in luteal weight and was highly significant $(P<0.01)$ when expressed both in absolute $\left(\mathrm{ml} \mathrm{min}^{-1}\right)$ and in relative $\left(\mathrm{ml}^{\circ} \mathrm{min}^{-1} .100 \mathrm{~g}^{-1}\right.$ tissue $)$ terms. The very large demands made by the functional CL on total ovarian blood flow was demonstrated by the data on the percentage distribution of flow within the ovaries. There was, however, no indication that the presence or absence of a CL influenced absolute rates of flow to either the follicular or stromal components of the ovary.

Blood flow rates in the stromal tissue of both ovaries were relatively uniform at about $160 \mathrm{ml}$. $\min ^{-1} .100 \mathrm{~g}^{-1}$ tissue; the apparently higher rates of stromal flow on Day 15 were not significantly different from the flow rates recorded on Days 14 or 16 of the cycle.

Total blood flow to the follicular component of both ovaries increased significantly $(P<0.05)$ from $637 \pm 81 \mathrm{ml} . \mathrm{min}^{-1} .100 \mathrm{~g}^{-1}$ tissue on Day 14 to $742 \pm 102$ on Day 15 and $1096 \pm 147 \mathrm{ml} . \mathrm{min}^{-1}$. $100 \mathrm{~g}^{-1}$ tissue on Day 16. This increase occurred to normal and atretic follicles and highlighted the marked similarity in the rate of flow to these two populations.

Table 2. Weights $(\mathrm{mg})$ and mean ( \pm S.E. M.) blood flows through capillaries $<15 \mu \mathrm{m}$ in diameter $\left(\mathrm{ml}^{\circ} \cdot \mathrm{min}^{-1} \cdot 100 \mathrm{~g}^{-1}\right)$ of different classes of ovarian follicles in sheep during the $72 \mathrm{hr}$ preceding ovulation

\begin{tabular}{|c|c|c|c|c|c|c|}
\hline $\begin{array}{l}\text { Follicular weight }(\mathrm{mg}) \\
\text { Follicular diameter }(\mathrm{mm})\end{array}$ & $\begin{array}{l}1 \cdot 0 \\
1 \cdot 8\end{array}$ & $\begin{array}{l}1 \cdot 0-2 \cdot 0 \\
1 \cdot 8-2 \cdot 4\end{array}$ & $\begin{array}{l}2 \cdot 0-3 \cdot 0 \\
2 \cdot 4-3 \cdot 0\end{array}$ & $\begin{array}{l}3 \cdot 0-5 \cdot 0 \\
3 \cdot 0-3 \cdot 8\end{array}$ & $\begin{array}{l}5 \cdot 0-10 \cdot 0 \\
3 \cdot 8-5 \cdot 3\end{array}$ & $\begin{array}{c}10 \cdot 0 \\
5 \cdot 3\end{array}$ \\
\hline \multicolumn{7}{|l|}{ Day 14} \\
\hline No. per group & 15 & 41 & 26 & 7 & 11 & 4 \\
\hline$\%$ of population & 14 & 39 & 25 & 7 & 11 & 4 \\
\hline Blood flow & $1003 \pm 303$ & $921 \pm 118$ & $432 \pm 60$ & $623 \pm 175$ & $460 \pm 64$ & $572 \pm 135$ \\
\hline \multicolumn{7}{|l|}{ Day 15} \\
\hline No. per group & 11 & 31 & 16 & 7 & 5 & 7 \\
\hline$\%$ of population & 14 & 40 & 21 & 9 & 7 & 9 \\
\hline Blood flow & $1697 \pm 354$ & $1237 \pm 147$ & $826 \pm 132$ & $731 \pm 211$ & $465 \pm 148$ & $461 \pm 85$ \\
\hline \multicolumn{7}{|l|}{ Day 16} \\
\hline No. per group & 26 & 68 & 33 & 9 & - & 10 \\
\hline$\%$ of population & 18 & 46 & 23 & 6 & - & 7 \\
\hline Blood flow & $1575 \pm 354$ & $1235 \pm 118$ & $1047 \pm 106$ & $614 \pm 110$ & - & $886 \pm 135$ \\
\hline
\end{tabular}

The distribution of blood to 'normal' follicles of different weights and diameters is given in Table 2. Two distinct trends are apparent. Mean blood flow increased significantly $(\boldsymbol{P}<0 \cdot 01)$ between Dâys 14 and 16 of the cycle, the increase being most marked at oestrus (Day 16). However, the flow rate decreased significantly $(P<0 \cdot 01)$ as the weight of the follicles increased. Thus, the follicle destined to ovulate received a lower rate of flow/g tissue than most other follicles. The variance due to the interaction of follicular weight and day of cycle was negligible. The percentage of follicles represented in each weight range was relatively consistent for the 3 days of the cycle.

\section{Discussion}

The rates of total ovarian blood flow reported in this paper are similar to those obtained by Mattner \& Thorburn (1974) using anaesthetized sheep and a venous outflow technique (Days 3-14, $7 \cdot 80 \pm 0 \cdot 48$; Day $16,2 \cdot 91 \pm 0 \cdot 25 \mathrm{ml} . \mathrm{min}^{-1}$ ), but are higher than those recorded by Brown, Hales \& Mattner (1974) in conscious ewes with radioactive microspheres (Day 9, 4.02 \pm 0.65 ; Day 16, $0.27 \pm 0.15 \mathrm{ml} . \mathrm{min}^{-1}$ ). Recent experiments confirm that ovarian flow rates, and in particular stromal flow rates, are lower in conscious than in anaesthetized ewes (B. W. Brown, personal communication; 
R. M. Moor \& B. P. Setchell, unpublished observations), but not in rabbits in which both the rate and distribution of ovarian flow are apparently unaffected by anaesthesia (N. W. Bruce \& C. P. Gibbs, unpublished observations).

There are major changes in the production of ovarian hormones during the follicular phase of the cycle. The most marked of these is the abrupt decline in progesterone production with the involution of the CL. By contrast, follicular activity is greatly enhanced and oestrogen output rises steadily to reach a peak on Day 15 and then falls sharply after the onset of oestrus (Cox, Mattner \& Thorburn, 1971). Changes in the functional capacity of the ovary are accompanied by major changes in the distribution of blood flow within the ovary. On Day $14,84 \%$ of total ovarian flow was directed to the luteal compartment but by Day 16 this had declined to $28 \%$, while blood flow to the follicles increased significantly between Day 14 and 16 . In the rabbit, however, it appears very unlikely that the fall in blood flow to the CL initiates involutionary changes within that organ (Bruce \& Hillier, 1974). Similarly, our present findings suggest that follicular development and maturation are not related to gross changes in follicular blood flow.

Although a major portion of the ovarian blood flow was directed to the functional CL, it nevertheless appeared to have little effect on absolute flow rates to the remainder of the ovary. Blood flow to the follicles and stroma were almost identical in both ovaries, despite the presence of a CL in only one of them. Furthermore, as luteal blood flow declined from $1122 \mathrm{ml} . \mathrm{min}^{-1} .100 \mathrm{~g}^{-1}$ tissue on Day 14 to $116 \mathrm{ml} . \mathrm{min}^{-1} .100 \mathrm{~g}^{-1}$ on Day 16 , flow rates to the stroma and follicles remained remarkably constant. We suggest that the $C L$ represents a low resistance shunt within the ovary. That changes in luteal flow do not affect flow rates to the stroma and follicles can be explained by postulating that the resistance to flow in the arteries supplying the ovary is comparatively low. Another explanation is that total ovarian blood fiow is always high, in the order of $10 \mathrm{ml} . \mathrm{min}^{-1}$, but that in the absence of a functional CL most of the arterial blood passes through arterio-venous shunts of greater than $15 \mu \mathrm{m}$ diameter.

Discounting the $\mathrm{CL}$, the stroma received the bulk of the remaining ovarian blood flow. Although stromal blood flow, about $150 \mathrm{ml} \cdot \mathrm{min}^{-1} .100 \mathrm{~g}^{-1}$, was low compared to the ovarian follicles and functioning $C L$, it was comparable with other organs in the body considered to have high flow rates; heart, $61 \mathrm{ml} . \mathrm{min}^{-1} .100 \mathrm{~g}^{-1}$; brain, $186 \mathrm{ml} \cdot \mathrm{min}^{-1} .100 \mathrm{~g}^{-1}$ and kidney, $178 \mathrm{ml} \cdot \mathrm{min}^{-1} .100 \mathrm{~g}^{-1}(\mathrm{~N}$. W. Bruce \& R. M. Moor, unpublished observations). The mean blood flow throughout the body was about $6.5 \mathrm{ml} \cdot \mathrm{min}^{-1} .100 \mathrm{~g}^{-1}$.

Since there was no evidence that the CL influenced follicular blood flow, the follicles from both ovaries were pooled to examine more closely the interaction between blood flow and follicular function. Three basic findings emerged from our results. Firstly, blood flow (ml. $\mathrm{min}^{-1} .100 \mathrm{~g}^{-1}$ tissue) to the follicles is exceptionally high and is of the same order as the rate of flow to a fully functional CL. Secondly, blood flow to the atretic follicles was maintained at a high level even during the advanced stages of follicular degeneration. Thus, although the involution of the $\mathrm{CL}$ is accompanied by a dramatic decline in blood flow, the involution of its cellular precursors, the granulosa cells, occurs in the presence of an exceptionally high follicular blood flow. Thirdly, the highest absolute blood flows ( $\mathrm{ml} . \mathrm{min}^{-1}$ ) occurred in the largest follicles, but the increase in the mass of tissue in these follicles was not matched by the increase in flow. Relative blood flow was, therefore, lower in the larger follicles than in the smaller ones at each stage of the cycle $(P<0.01)$, indicating that the larger follicles, including the one destined to ovulate, do not receive a preferential blood supply. We have extended these observations (N. W. Bruce \& R. M. Moor, unpublished observations) to show that the $30-40 \%$ of small follicles that are rapidly stimulated by the injection of gonadotrophin (see Moor, Hay, Caldwell \& McIntoch, 1973) do not receive a higher rate of blood flow than the $60-70 \%$ of follicles that are not activated by the hormone. There is, therefore, little evidence at present to support the contention that changes in blood flow play an important role in the control of follicular function.

We thank Dr G. S. Dawes and Professor T. R. R. Mann for advice and Mr D. Green for skilled technical assistance. One of us (N.W.B.) is indebted to the Medical Research Council for financial support. 


\section{References}

Abdul-Karim, R.W. \& Bruce, N.W. (1973) Blood flow to the ovary and corpus luteum at different stages of gestation in the rabbit. Fert. Steril. 24, 44-47.

Brown, B.W., Hales, J.R.S. \& MattNer, P.E. (1974) Capillary blood flow in sheep ovaries, measured by iodoantipyrine and microsphere techniques. Experientia 30, 914-915.

BRUCE, N.W. \& Hillier, K. (1974) Effect of PGF P $_{2 \alpha}$ on ovarian blood flow and corpus luteum regression in the rabbit. Nature, Lond. 249, 176-177.

Buckberg, G.D., Luck, J.C., PAYNe, D.B., Hoffmann, J.I.E., ARChIE, J.P. \& Fixl.er, D.E. (1971) Some sources of error in measuring regional blood flow with radioactive microspheres. $J$. appl. Physiol. 31, 598-604.

Cox, R.I., Mattner, P.E. \& Thorburn, G.D. (1971) Changes in ovarian secretion of oestradiol-17 $\beta$ around oestrus in the sheep. J. Endocr. 49, 345-346.
Mattner, P.E. \& Thorburn, G.D. (1969) Ovarian blood flow in sheep during the oestrous cycle. $J$. Reprod. Fert. 19, 547-549.

Moor, R.M., Hay, M.F., Caldwell, B.V. \& McIntosh, J.E.A. (1973) Effect of gonadotrophins on the production of steroids by sheep ovarian follicles cultured in vitro. J. Endocr. 58, 599-611.

Rudolf, A.M. \& Heymann, M.A. (1972) Measurement of flow in perfused organs using microsphere techniques. Acta endocr., Copenh., Suppl. 258, 112-123.

Seamark, R.F., Moor, R.M. \& McIntosh, J.E.A. (1974) Steroid hormone production by sheep ovarian follicles cultured in vitro. J. Reprod. Fert. 41, 143-158.

SzEGo, C.M. (1965) Role of histamine in mediation of hormone action. Fedn Proc. Fedn Am. Socs exp. Biol. 24, 1343-1352.

WURTMAN, R. J. (1964) An effect of LH on the fractional perfusion of the rat ovary. Endocrinology 75, 937-939

Received 28 May 1975 